\title{
Constantin Stanislavski e o Estúdio de Ópera do Teatro Bolshoi: percursos e pensamentos sobre ópera
}

Constantin Stanislavski and the Opera Studio of the Bolshoi Theatre: pathways and thoughts about opera

por Rosane Faraco Santolin

RESUMO

0 objetivo deste artigo é apresentar o percurso do renomado ator e diretor de teatro Constantin Stanislavski em suas atividades operístico-musicais e, de forma especial, o Estúdio de ópera que ele dirigiu a partir de 1918. Stanislavski teve um envolvimento com ópera e musicais desde a infância, como espectador, e posteriormente como cantor-ator amador, diretor do Conservatório Musical de Moscou e diretor do Estúdio de Ópera do Teatro Bolshoi. 0 mestre russo levou para o campo da ópera as suas pesquisas e seu "sistema" de atuação, fazendo com que os cantores desenvolvessem suas aptidões como atores e buscassem uma maior interação entre os elementos da cena, da voz e da música. Seu treinamento no Estúdio de ópera culminou em diversas apresentações e montagens de óperas, apresentadas no espaço do Estúdio e no Teatro de Arte de Moscou.

Palavras-chave ópera; Stanislavski; cantor-ator; Teatro Bolshoi

\section{ABSTRACT}

The objective of this article is to show the route of the renowned actor and theater director Constantin Stanislavski in his operatic and musical activities and, especially, the Opera Studio he directed since 1918. Stanislavski had an involvement with opera and musicals since childhood, as a spectator, and later as an amateur singer-actor, as director of the Moscow Conservatory of Music and as director of the Opera Studio of the Bolshoi Theatre. The Russian master took to the field of opera his research and his "system" of acting, making the singers develop their skills as actors and seek greater interaction between the elements of the scene, voice and music. His training in the Opera Studio culminated in several presentations and operas assemblies, presented in the Studio room and in the Moscow Art Theatre.

Keywords opera; Stanislavski; singer-actor; Bolshoi Theatre 


\section{A infância e juventude artística}

Constantin Siergueivitch Alexeiev, que ao iniciar sua vida no teatro passou a usar o codinome de Constantin Stanislavski, nasceu em Moscou, na Rússia, em 05 de janeiro de 1863. Nascido em uma família financeiramente abastada, ele teve uma infância privilegiada em termos culturais. Desde cedo frequentou o circo, a ópera, o teatro, o balé. Sua família geralmente possuía assinatura para toda a temporada de ópera de São Petersburgo. Assim, o ainda pequeno Stanislavski assistiu a muitas montagens de ópera com bons cantores, e como afirma em sua biografia, ele assistiu aos "melhores cantores de ópera do mundo" (STANISLAVSKI, 1989, p. 34).

0 diretor certifica, em Minha Vida na Arte (1989), que diversas impressões vividas na infância contribuíram para o seu desenvolvimento e acuidade artística futura, e destaca que a ópera lhe deixou impressões fortes, além de uma influência benéfica ao seu ouvido, gosto e olhar teatral. Abaixo transcrevo um pequeno relato sobre a sua lembrança de tais espetáculos, do período de sua infância, quando recordados na vida adulta:

As impressões causadas pelos espetáculos da ópera italiana continuavam vivas em mim com uma intensidade extraordinária, evidentemente bem maior que a daquelas deixadas pelo circo. Creio que isto se deve ao fato de que a própria intensidade das impressões era imensa. Naqueles idos eu não tinha consciência dela, apenas a percebia de forma orgânica e inconsciente tanto espiritual quanto fisicamente. Só mais tarde vim entender e valorizar essas impressões, ao rememorá-las. Já o circo nos divertia e alegrava na infância, mas as recordações dele não constituíam interesse na idade madura, e eu as esqueci (STANISLAVSKI, 1989, p. 34, grifo da autora).

Observa-se que, coerentemente com o seu pensar sobre o trabalho de ator, Stanislavski destaca, com ênfase, a importância das primeiras impressões, e como elas podem ser reavivadas num "corpo" emotivamente preparado para a cena. A experiência como espectador de ópera proporcionou ao futuro diretor a compreensão do valor dessas imagens e sensações iniciais que marcam o corpo e o espírito do artista. Outro exemplo curioso sobre suas memórias é que, em 1911, trinta e cinco anos após ter assistido ao barítono Cotoni representar em Moscou, ele o reconheceu, apenas pela voz, passeando aleatoriamente em Roma:

[...] caminhava com um amigo por uma travessa estreita. De repente vem do andar superior de uma casa uma nota: ampla, sonora, agitada, cálida e emocionante. E eu voltei a experimentar fisicamente a sensação conhecida. "Cotoni!" - exclamei.

"É verdade, ele mora aqui - confirmou o meu conhecido. - Como tu o reconheceste?" - perguntou surpreso.

"Eu o senti, - respondi. - Coisa como essa a gente nunca esquece" (STANISLAVSKI, 1989, p. 35-36).

É possível notar o quanto a ópera foi importante para Stanislavski, deixando lem- 
branças muito fortes e desde a infância corroborando com a percepção de si mesmo que o mestre tanto irá desenvolver ao longo de sua carreira. Além do seu contato como espectador de ópera, ele também participou de montagens de operetas e vaudevilles em seu teatro amador, no Círculo Aleksêiev (grupo de amadores e familiares de Stanislavski), no qual atuou de 1877 a 1887. Tal feito se deve ao teatro que o pai de Stanislavski construiu na residência familiar:

Com 14 anos de idade, Stanislavski registra a inauguração da sala que seu pai havia construído para acolher as apresentações da família. 0 espaço continha, além do palco e do auditório, salas laterais onde ficavam os camarins, o guarda-roupa e a oficina de cenários e adereços. A grande noite de abertura apresentou um repertório de quatro peças breves, nas quais participaram o pai de Stanislavski, os irmãos, os primos, os amigos e a governanta. (TAKEDA, 2008, p. 28).

Aos 14 anos Stanislavski fez o primeiro registro escrito de seu fazer teatral relatando, justamente, o espetáculo de inauguração desse espaço, o vaudeville, em um ato, A Xícara de Chá. Além de atuar como ator, Stanislavski também assumiu a direção de operetas com o Círculo de Aleksêiev. Em 1884 atuou e dirigiu a opereta Mascotta, na qual fez o papel de Pino.

0 envolvimento com a música e o teatro, nos vaudevilles e operetas, o levaram a estudar canto, e ambicionar ser cantor de ópera.

Ele relata em Minha vida na arte que sonhara fazer carreira como cantor de ópera e que chegara a fazer aulas de canto com Fiódor Pietrovitch Komissarjevski, famoso tenor da época e pai da atriz vera Komissarjevskia. Desse período, há em seus arquivos um manuscrito datado de 1885 e intitulado "Devaneios sobre a forma como eu conceberia e interpretaria o papel de Mefistófeles na ópera Fausto de Gounod. (TAKEDA, 2008, p. 46).

Ao relatar esse período, Stanislavski lembra que nele houve uma efervescência nacional, onde a ópera russa "entrou em animação. Tchaikovsky e outros astros do mundo da música passaram a compor para o teatro. Entreguei-me ao envolvimento geral, imaginei-me cantor e comecei a preparar-me para a carreira na ópera" (Stanislavski, 1989, p. 130). Mas, com as dificuldades verificadas nas aulas com Fiódor Pietróvitch Komissarjevsky, ele acabou desistindo desta carreira, e chegou à conclusão de que suas aptidões vocais não eram as ideais para a ópera. Contudo, ele ainda insistiu na opereta, e em 1887 destacou-se no papel de Nanki-Pu na opereta Mikado, do compositor inglês Arthur Sullivan (1842-1900), com libreto de W.S. Gilbert (1836-1911).

Sobre o seu trabalho com vaudeville e operetas o Stanislavski aponta:

A opereta e o vaudeville são uma boa escola para os artistas. Não é por acaso que os velhos, nossos precursores, começaram por eles a sua carreira, neles aprenderam arte dramática e construíram a técnica artística. [...] A vantagem deste gênero consiste em que, requerendo grande 
técnica externa e assim elaborando-a, ele não sobrecarrega violentamente a alma com sentimentos fortes e complexos, não colocam diante dos jovens atores questões criativas acima das suas possibilidades. (STANISLAVSKI, 1989, p. 114).

Ele pontua a necessidade do ator ter caminhos para iniciar a sua carreira artística e as operetas e vaudevilles seriam uma forma técnica de adentrar nesse mundo, que, para ele, requer muito trabalho emocional. 0 trabalho com tais gêneros possibilitou à Stanislavski, nas palavras de Bonfitto (2002, p. 22), ter pela primeira vez a percepção da "importância do trabalho rítmico na construção da ação".

Apesar de abandonar as aulas e a pretensão de tornar-se cantor de ópera, Stanislavski manteve um estreito vínculo com o ex-professor:

As aulas de canto cessaram, mas eu não deixei de ir, quase diariamente, à casa do meu ex-professor [...], para conversar com ele sobre arte $e$ encontrar pessoas ligadas à música e ao canto, professores do Conservatório onde Komissarjevski dirigia as classes de ópera e eu figurava ainda como um dos diretores. Revelando um segredo, digo que eu alimentava cá comigo a atrevida idéia de fazer-me auxiliar de Komissarjevski nas aulas de ritmo, que eu inventara para mim. É que eu não conseguia esquecer a impressão encantadora que conservara dos ensaios de ópera, do efeito do ritmo ao som da música. Não podia deixar de perceber que os cantores davam um jeito de combinar ao mesmo tempo vários ritmos totalmente diversos: a orquestra e o compositor mantêm seu ritmo, o canto segue por vias obrigatoriamente paralelas a ele, mas o coro levanta e baixa automaticamente os braços em outro ritmo, assume um terceiro ritmo; dependendo do estado de ânimo, cada cantor atua, ou melhor, nada faz em seu ritmo, ou, mais exatamente, em qualquer ritmo.

Demonstrei a Komissarjevski a necessidade de cultivar o ritmo físico para o cantor. Ele se deixou levar por minha idéia. Já encontraríamos acompanhador-improvisador e passávamos fins de tarde inteiros em movimento, sentados ou calados em ritmo.

Infelizmente o Conservatório não permitiu que Komissarjevski organizasse a turma projetada e os nossos ensaios cessaram. Mas desde então eu mal escuto música, sinto irromperem em mim movimentos rítmicos e mímica nas mesmas bases em que me parecia ouví-los naquele tempo. [...] Percebendo o campo do ritmo mas sem ter plena consciência dele, esqueci-o por algum tempo (STANISLAVSKI, 1989, p. 131-132).

Se não podia desenvolver-se como cantor de ópera, Stanislavski elaborou, a partir de seus estudos com a música, um pensamento e uma prática refinada da noção tempo-ritmo voltado para o trabalho do ator, que é o alicerce fundamental da musicalidade em cena. Externamente o tempo-ritmo aparece no corpo do ator por meio das ações físicas; internamente, pelas vivências interiores (FERNANDINO, 2008).

0 envolvimento com a área musical fez com que Stanislavski fosse convidado a 
assumir em 1885, a direção da Sociedade Musical Russa', em conjunto com mais cinco diretores. Ele revelou, dentro de sua natureza observadora de ator, que sua condição de diretor lhe dava a oportunidade de conhecer "pessoas notáveis e de talento como Anton Grigorievitch Rubinstein e outros, que [...] causavam grande impressão e tiveram importância considerável" (1989, p. 72) para o seu futuro artístico.

Mesmo a comunicação superficial com grandes homens, a simples proximidade deles, a troca invisivel de correntes espirituais, às vezes até a sua relação inconsciente com esse ou aquele fenômeno, algumas exclamações ou palavra lançada a êsmo e a pausa eloqüente deixam a sua marca em nosso espírito. Posteriormente, ao desenvolver e deparar-se com fatos análogos na vida, o artista recorda o olhar, palavras, exclamações $e$ pausas de um grande homem, decifra-as e interpreta os seus verdadeiros sentidos (STANISLAVSKI, 1989, p. 72).

o período em que Stanislavski atuou junto ao Círculo Aleksêiev (1877-1887) corresponde a sua formação no círculo familiar e amador. Mas, mesmo nessa fase formativa, o que se percebe é um diferencial nesse jovem em relação a outros amadores em formação. Stanislavski desenvolve uma apurada capacidade de auto-observação e uma técnica, que com o tempo ficou muito sofisticada, de registrar as experiências e avançar em seus procedimentos crítico-analíticos. Essa fase em sua vida - no Círculo, em seus estudos musicais e no trabalho na Sociedade Musical Russa - contém as bases para a posterior elaboração do sistema para o trabalho do ator, e foi depurada com o trabalho, também posterior, desenvolvido como diretor de ópera. A questão da música, do ritmo e do tempo faz parte desde a formação inicial desse diretor, e essas noções se tornaram vitais para o desenvolvimento de seu sistema para a formação do ator e no seu trabalho na ópera.

Vários procedimentos de pesquisa para o ator e para a cena Stanislavski aprofundou nos dez anos, de 1888 a 1898, em que atuou como ator e diretor na Sociedade de Arte e Literatura. Seu trabalho seria profissionalmente realizado e devidamente experimentado nos anos seguintes, com o Teatro de Arte de Moscou.

\section{Os encaminhamentos da pesquisa para 0 ator/cantor}

Junto com Vladimir Ivanovich Niemirovitch-Dantchenko (1858-1943), Stanislavski fundou o Teatro de Arte de Moscou (TAM), em 1898. Lá ele desenvolveu procedi-

1 A Sociedade Musical Russa foi fundada em 1859 por Anton Grigorievitch Rubinstein, e em 1862 ele fundou Conservatório de S. Petersburgo (a primeira escola de música na Rússia). Fonte: http:// pt.wikipedia.org/wiki/Anton_Rubinstein. Acesso em: 11 ago. 2012. 
mentos cênicos para interpretação e criação do ator, "com o objetivo de renovar práticas tradicionais de encenação cujas bases concentravam na reprodução de modelos" (FERNANDINO, 2008, p. 30). Dentre os objetivos do TAM, estava criar um teatro nacional, onde se pretendia renovar a cena teatral russa e, ao mesmo tempo, abrir espaço para o chamado público "popular" (GUINSBURG, 1985).

Já nos primeiros anos do TAM, Stanislavski aplicou novas formas de concepção de espetáculo teatral, onde "a música deveria ser composta em função de cada espetáculo especificamente, e os figurinos deveriam ser submetidos, quando necessário, a uma pesquisa histórica" (BONFITTO, 2002, p. 22, grifo da autora). 0 trabalho de ator, entretanto, ainda era pouco desenvolvido pelo diretor russo e os modelos por ele utilizados ainda eram os "tradicionais", ou seja, onde há a reprodução de um modelo já pronto. Com os primeiros textos encenados, especialmente os de Anton Tchékhov (1860-1904), uma nova estrutura foi sendo montada por Stanislavski, no que diz respeito à formação da personagem pelo ator e essas ideias se basearam inicialmente de processos interiores do artista.

A primeira fase de Stanislavski, conhecida como "Linha das Forças Motivas", onde o desenvolvimento criativo do ator está centrado no processo interior e, de maneira importante, na memória emotiva, dá-se até o início do envolvimento do diretor com o Estúdio de ópera do Teatro Bolshoi. Tal desenvolvimento aconteceu junto a esta experiência de Stanislavski em função do aperfeiçoamento da ação rítmica com os cantores, e a memória emotiva vai deixando de ser o centro do desenvolvimento criativo do ator para dar lugar à ação física. 0 ritmo teria um papel muito importante em seu trabalho e central no trabalho com os cantores do Estúdio. Das várias conclusões as quais Stanislavski chegou com o seu trabalho no período, a seguinte diz respeito estritamente às questões da ópera: "Para unificar a música, o canto, a palavra e a ação é necessário não um tempo-ritmo físico externo, mas interno, espiritual" (STANISLAVSKI, 1989, p. 515). Dessas palavras, pode-se perceber que Stanislavski não estava esquecendo o envolvimento interior que 0 ator deveria ter, até então por ele desenvolvido; mas, que o ritmo não deveria ser algo dado apenas exteriormente, ou ditado apenas pela música. É possível observar, assim, que a ação física por ele desenvolvida no período é uma interação psicofísica do ator para a construção da sua personagem e que o tempo-ritmo não é dado apenas externamente, mas é parte da construção interior.

0 TAM figura como importante na história do teatro em virtude de diversos fatores, dentre eles, as mudanças que lá foram propostas. Há que se levar em conta que todo um processo de treinamento de atores foi assim desenvolvido de forma a ir-se eliminando o "estrelismo das divas". Além de uma proposta de trabalho de ator, tentou-se reconhecer que o mesmo é um ofício e que possui métodos e procedimentos para treinamento. As montagens do TAM ora realistas, naturalistas ou simbolistas, eram imbuídas de propósitos artísticos que revolucionaram toda uma era teatral. Os mesmos preceitos, de treinamento e ofício, Stanislavski desenvolveria no Estúdio de ópera do Teatro Bolshoi. 


\section{Estúdio de Ópera do Teatro Bolshoi}

0 trabalho de Stanislavski com a ópera iniciou em 1918, a partir de um convite feito por Elena Konstantinova Malinovskaya, diretora dos Teatros Acadêmicos Estatais de Moscou, para que o TAM e o Teatro Bolshoi firmassem uma parceria de atuação conjunta. E.K. Malinovskaya desejava "pôr na devida altura o aspecto dramático dos espetáculos de ópera do Teatro Bolshoi". (STANISLAVSKI, 1989, p. 510).

0 Estúdio tinha, portanto, como objetivo melhorar a cultura teatral dos cantores de ópera, de modo que houvesse uma reforma nos espetáculos realizados na época, ou seja, que se fugisse dos clichês conhecidos e que se trouxesse mais verdade nas atuações. Com "verdade" entende-se aqui não apenas o sistema desenvolvido por Stanislavski e suas teorias e práticas teatrais nesse momento e Estúdio específicos, mas um envolvimento maior de cada cantor com as cenas e o palco; que se igualasse a preocupação com a técnica do canto e o papel de ator. Conforme Stanislavski (1989) já havia constatado em sua juventude, os gestos vazios e sem sentido, apesar de consagrados, eram desprovidos de ação e atitude no palco, e, dentro de suas ideias, insuficientes para a arte dramático-musical.

O Estúdio começou com um pequeno grupo de cantores do Teatro Bolshoi. Os primeiros eventos promovidos entre os grupos foram para mostrar as suas habilidades, em forma de confraternização, regada, não sem alguma dificuldade, por comida e bebida.

Antes de avançar sobre o percurso operístico de Stanislavski é necessário fazer, entretanto, uma breve pausa. Pois, merece um breve destaque o panorama da Rússia no período de criação do Estúdio de ópera. 0 país estava em fins da Primeira Guerra Mundial e internamente fervilhante por conta da Revolução Russa de 1917. Havia escassez de alimentos, racionamento de gêneros essenciais. Os artistas precisavam trabalhar mais, dar mais concertos, para conseguirem se manter. Os primeiros cantores a frequentar o Estúdio de ópera, conforme mencionado, eram cantores já participantes do Teatro Bolshoi e, segundo Stanislavski, este grupo:

[...] fez grandes sacrifícios em prol da nossa iniciativa e se comportou heroicamente. Todos trabalhavam de graça, e ainda por cima num período em que a vida não entrara nos eixos após as primeiras tempestades revolucionárias. Muitos cantores dotados de vozes maravilhosas eram forçados a caminhar pela neve e na umidade sem galochas, com calçados gastos. E mesmo assim faziam tudo o que estava ao seu alcance para frequentar as aulas do Estúdio.

Mas havia condições contra as quais eles não podiam lutar. Suas apresentações frequentes nos espetáculos de ópera do Teatro Bolshoi eram um obstáculo insuperável às suas aulas regulares no Estúdio: eram constantemente desviados, ainda pelos concertos que davam para garantir um pedaço de pão (1989, p. 511). 
Stanislavski (1989) comenta sobre essas dificuldades oriundas do caos interno do país e relata que, durante o inverno de 1919, os ensaios nunca eram compostos pelos quatro cantores de um quarteto que estavam tentando ensaiar: os horários de cada cantor eram diversos e eles ou tinham que faltar, ou saíam correndo na metade do ensaio, ou chegavam atrasados, para realizarem os concertos e apresentações de ópera do Teatro Bolshoi.

No ano seguinte, entretanto, o Estúdio tomou uma nova configuração e passou a cuidar de novos cantores oriundos do Conservatório de Música de Moscou, que tinham interesse em entrar para o Teatro. 0 Estúdio passou a ser, assim, um passaporte para a vida profissional do Bolshoi:

[...] pedi permissão para recrutar um quadro de jovens do Estúdio, que antes de ingressarem ali como artistas fariam várias disciplinas sobre a minha direção. Uma vez autorizado, pus mãos à obra. 0 primeiro a fazer foi elaborar um programa de ensino para o curso de ópera de acordo com as minhas deliberações [...] (STANISLAVSKI, 1989, p. 512).

Os cantores tinham que passar, dessa maneira, pelas aulas e preparação corporal e cênica para poderem participar das montagens de ópera, dirigidas por Stanislavski. Esta pré-condição instituída pelo diretor russo para a realização das montagens parece ter sido assim colocada para evitar que os cantores envolvidos no Estúdio apenas o usassem para aprender "truques" e técnicas breves para o palco, ou para apenas ensaiar suas partes numa das produções. Segundo o mestre russo,

A maioria dos cantores só pensa no "som", como eles mesmos denominam a nota bem tirada e lançada ao público. Eles precisam do som pelo som, de uma boa nota pela boa nota.

Com semelhantes concepções do trabalho operístico entre a maioria dos cantores, a cultura musical e dramática se encontrava num estágio primitivo, diletante. Muitos deles só precisavam do Estúdio de ópera para aprender a caminhar pelo palco, saber "como se interpreta certo papel", passar o repertório, e, fazendo-o de ouvido com o auxílio de um acompanhante, decorar algumas partes e a mise-em-scène com as suas fancarias ou usar o Estúdio para chegar ao Teatro Bolshoi.

Compreende-se naturalmente que o novo Estúdio não havia sido criado para gente daquela espécie (1989, p. 512-513).

Apesar da pouca informação encontrada a respeito dos assistentes de Stanislavski no Estúdio, ao menos no início dos trabalhos encontrava-se a presença de seus irmãos Zinaïda Sokolova e Vladimir Alexeyev. Sokolova ajudava na criação das personagens a partir da criação da "partitura interior" e "vida interior" do papel (STANISLAVSKI; RUMYANTSEV, 1998). Já Alexeyev trabalhava como pianista e ajudava na parte rítmica, além de seu auxílio junto com sua irmã nas aulas sobre o "sistema". Além destes, encontravam-se, para a parte vocal, a então famosa atriz do Teatro Bolshoi M.G. Gukova, junto com A.V. Bogdanovitch; na direção vocal do Estúdio E.I. Zbruiev e I.V. Pietrov; a parte musical estava a cargo do regente do Teatro Bolshoi, 
N.S. Golovanov, após passando para V.I. Suk. Já S.M. Volkonski e N.M. Safonov lecionavam dicção, ou "as leis da fala e a palavra aplicada à arte vocal" (STANISLAVSKI, 1989, p. 515). Na parte de dança e plasticidade de movimentos, a orientação era dada por A.A. Pospiekhin, membro do corpo de balé do Teatro².

0 Estúdio mais tarde se separaria do Teatro Bolshoi e passaria a se chamar, após 1924, Estúdio de ópera de Stanislavski; em 1926, Estúdio-Teatro de ópera; e, em 1928, Teatro de ópera de Stanislavskỉ.

A primeira produção pública do Estúdio foi em 1921, no palco do Teatro de Arte de Moscou (STANISLAVSKI; RUMYANTSEV, 1998) e foi intitulada "Uma noite de Rimski-Korsakov". Há que se ressaltar que Stanislavski, já renomado por suas atividades junto ao TAM, estava causando muita curiosidade aos envolvidos do meio musical e operístico em virtude de suas experiências com o Estúdio. Essa performance:

[...] seria não apenas importante, mas decisiva. Muitas pessoas de teatro haviam escutado sobre os experimentos de Stanislavski com ópera e estavam aguardando ansiosamente e com interesse a apresentação pública. Alguns tinham preconceito contra eles e outros estavam esperançosos $e$ com animadas expectativas. Os bastidores dos Teatros de Moscou estavam cheios de rumores sobre o método de trabalho de Stanislavski com os cantores, já que descrições parciais sobre o mesmo tinham vazado e dado munição para aqueles que eram contra e aqueles que eram a favor de mudanças (STANISLAVSKI; RUMYANTSEV, 1998, p, 39)4.

Por ser a primeira aparição do Estúdio e ainda por ter sido cedido o palco do Teatro de Arte de Moscou para a mesma, havia bastante ansiedade e responsabilidade por parte dos jovens cantores, até então desconhecidos e apenas ligados ao nome do renomado diretor russo. No repertório escolhido estava o prólogo de $A$ dama de Pskov e cenas de 0 conto do czar Saltan e A noite de Natal, de Rimski-Korsakov (1844-1908). A escolha de tais trechos não foi aleatória: eles necessitavam de "verdadeira atuação", o que era não apenas um desafio, mas uma forma de colocar em prática os ensinamentos que estavam recebendo no Estúdio.

A recepção do espetáculo foi boa já que, segundo Rumyantsev, "deve ser dito de uma

2 Tais nomes, alguns encontrados em Stanislavski on Opera (1998) e outros em Minha Vida na Arte (1989), são de difícil acesso, sendo que pouco ou nenhum material foi encontrado sobre eles, nem mesmo datas de vida e morte.

3 Os respectivos nomes e datas foram tirados do livro Stanislavski on Opera, 1998, p. X., e foram livremente traduzidos pela autora de, respectivamente: Stanislavski Opera Studio; Opera Studio-Theatre e Stanislavski Opera Theatre.

4 [...] would not be only important but decisive. Many theatre people had heard of Stanislavski's experiments with opera and were looking forward with interest to their public presentation. Some were prejudiced against them and some were filled with hope and lively expectation. The wings in Moscow's theatres were full of rumors about Stanislavski's method of work with singers, since partial descriptions of it leaked out and gave ammunition to those who were against and those who were for change. 
só vez que a forma de ensinar a atuar e dirigir de Stanislavski era tão poderosa que a audiência ouviu o prólogo de $A$ dama de Pskov com respiração suspensa, e riram ruidosamente com o cômico Czar Saltan" (STANISLAVSKI; RUMYANTSEV, 1998, p. 39)5.

A próxima produção, na mesma temporada, foi Uma noite de Pushkin, desta vez homenageando o romancista e poeta russo Alexander Sergueievitch Pushkin (1799-1837). Dentre os trechos escolhidos, estavam três cenas de Eugene Onegin, ópera do compositor Tchaikovsky - e o prólogo de 0 conto do czar Saltan, ambos com texto de Pushkin.

No balanço da conta dessa primeira temporada do Estúdio é necessário dizer que ela não era ainda um evento histórico na vida do teatro de Moscou. Ainda assim, havia um número de especialistas que perceberam que nesses "esboços", na especial aproximação de Stanislavski com a ópera, nos seus esforços em combinar a música com as palavras e ambas com os movimentos rítmicos dos cantores-atores, eles poderiam experenciar novas reações a óperas famosas (STANISLAVSKI; RUMYANTSEV, 1998, p. 41-42, grifo da autora) 6 .

Vale lembrar que a proposta do Estúdio era renovar as práticas de ópera do período. Este era um objetivo não apenas do Estúdio, mas primordialmente de Stanislavski, em todos os seus trabalhos, sejam eles operísticos ou não. E é importante pontuar, desde já, que Stanislavski conseguiu de fato promover mudanças significativas no cenário operístico russo.

Dentre outras produções realizadas pelo Estúdio - algumas no próprio salão dos ensaios - estão: Werther, em agosto de 1921, de Jules Massenet com libreto de Édouard Blau, Paul Milliet e Georges Hartmann; Eugène Onegin, em junho de 1922, de Tchaikovsky com libreto do próprio compositor, seu irmão Modest, e Constantin Shilovsky; e 0 casamento secreto, em abril de 1926, de Cimarosa, com libreto de Giovanni Bertati.

Após a separação do Estúdio com o Bolshoi, outras produções foram realizadas, tais como A noiva do czar, em novembro de 1926, de Rimsky-Korsakov, com libreto de Il'ya Tyumenev; La Bohème, em abril de 1927, de Giacomo Puccini, com libreto de Luigi Illica e Giuseppe Giacosa; Uma Noite de Maio, em janeiro de 1928, de Rimski-Korsakov com libreto do próprio compositor; Boris Godunov, em março de 1928, de Modest Mussorgsky, baseado na história homônima de Pushkin e na História do Estado Rus-

5 It must be said at once that Stanislavski's way of teaching acting and od firecting was so powerful that the audience listened to The Maid of Pskov with bated breath, and they laughed loudly at the comic Tsar Saltan.

6 In balancing the account of this first season of the Studio it is necessary to say that it was not yet an epoch-making event in the thatre life of Moscow. Still there were a number of experts who realized that in these "sketches", in Stanislavski's special approach to opera, in his efforts to blend music with the words and both with the rhythmic movements of the actor-singers, they could experience new reactions to well-known operas. 
So de Karamzin (Kobbé, 1997, p. 479); A dama de espadas, em fevereiro de 1930,de Tchaikovsky, com libreto de Modest Tchaikovsky; O Galo de Ouro, em maio de 1932, de Rimsky-Korsakov com libreto Vladimir Belsky. Nessas duas últimas produções, Stanislavski não teve tanta frequência nos ensaios devido ao seu frágil estado de saúde. Apenas as produções até 1928 foram inteiramente regidas pelo mestre russo. Após a morte de Stanislavski, Vsevolod Meyerhold (1874-1940) completou a ópera elas Rigoletto, em março de 1939, de Giuseppe Verdi, com libreto de Francesco Maria Piave.

Em 1941 foi criado o Teatro Musical de Moscou Stanislavski e Nemirovitch-Dantchenko', a partir da união definitiva do Teatro de ópera de Stanislavski com o Teatro Musical Vladimir Nemirovitch Dantchenko e nele prevalecendo as ideias principais de Stanislavski e Dantchencko. Até hoje, são representadas produções operístico-musicais, além de balés. 0 local é o mesmo teatro onde o Estúdio tomou parte em 1926, o Teatro Dmistrovski.

\section{Algumas práticas do Estúdio}

Os cantores-atores, como assim eram designados por Stanislavski, passavam por um treinamento que envolvia desde exercícios mais simples, de percepção espacial e relaxamento e percepção corporal, liberação das tensões do corpo desnecessárias ao ofício do ator, aprendizagem de danças e esgrima, além de dicção e a prática do canto com árias e baladas românticas (STANISLAVSKI; RUMYANTSEV, 1998). Muitos exercícios eram desenvolvidos com música, de forma a trabalhar também o tempo-ritmo.

Este treinamento desenvolvido com os cantores-atores do Estúdio consistia em uma rotina dividida, diariamente, em atividades em grupo e exercícios, e a outra metade na preparação de performances. Dentre as atividades sugeridas por Stanislavski para a preparação dos cantores, estavam, de maneira importante e como citado acima, a consciência do corpo e o relaxamento do mesmo, partindo de alongamentos para a eliminação das tensões desnecessárias. Stanislavski parecia dedicar boa parte desse tempo de treinamento com exercícios de alongamento relativamente simples, mas que traziam consciência e que ajudassem, assim, aos cantores-atores adquirirem plasticidade de movimento (STANISLAVSKI; RUMYANTSEV, 1998). A fim de se conseguir uma mobilidade dos corpos, os exercícios diários eram dedicados para liberar especialmente tensões nos braços, pulsos e dedos. "Eles eram todos feitos com música, para treinar os cantores a fazer cada movimento consonante com os ritmos musicais" (STANISLAVSKI; RUMYANTSEV, 1998, p.

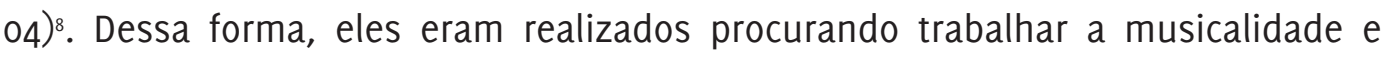

7 www.stanmus.com

8 "They were all done to music in order to train the singers in making every movement consonant with musical rhythms". 
plasticidade dos movimentos dos cantores ao mesmo tempo em que relaxavam as tensões. Stanislavski diferia essas tensões das contrações musculares inerentes à técnica do canto, tais como o trabalho diafragmático, dos músculos intercostais, ou da laringe: essas seriam para ele as "contrações de trabalho" tes ao canto. Ele fazia com que os cantores tratassem de encontrar eles mesmos a diferenciação entre essas tensões, já que, quando um artista "está atuando de acordo com os seus sentimentos interiores, ele não deve ser impedido, em seus movimentos, por contrações musculares. Toda a atenção do cantor deve estar centrada na sua ação" (STANISLAVSKI; RUMYANTSEV, 1998, p. 04) ํ.

Os exercícios propostos, desde os mais primários e mecânicos, deveriam ser realizados não apenas plasticamente, ou seja, deveriam ter "[...] alguma relação criativa com o que estava sendo feito" (STANISLAVSKI; RUMYANTSEV, 1998, p. 07)". Stanislavski sugeria aos seus aspirantes que cada exercício, por mais simples que fosse, trabalhasse a criatividade interior e tivesse um propósito que não fosse um fim em si mesmo, ou a beleza plástica em si mesma. Além disso, era necessário que cada cantor-ator adquirisse controle sobre seu aparato físico, mental e emocional para não apenas um bom desempenho no palco, mas também para que a via de comunicação criativa estivesse aberta para a atuação.

Exercícios de caminhada, assim como aqueles usados por atores no TAM, eram realizados diariamente com objetivos parecidos com os de "não-cantores": aquecer o corpo, gerar atenção ao espaço, observação do corpo, controle do corpo. "0 cantor-ator os necessita completamente assim como ele faz seus vocalizes diários, Stanislavski diria" (STANISLAVSKI; RUMYANTSEV, 1998, p. 06). ${ }^{2} 0$ diretor queria que os cantores-atores do Estúdio obtivessem um senso de trabalho artístico que fosse além dos cuidados vocais. Para trabalhar com ópera, eles precisariam estar aptos a "devidamente" atuar além de cantar. E da mesma forma a qual um cantor deveria se exercitar vocalizando diariamente, para Stanislavski os exercícios de caminhada também deveriam proceder com igual importância; aprender a caminhar com "graciosa fluidez"

As caminhadas que eram realizadas com música poderiam partir de um andamento lento, realizando os passos da maneira mais vagarosa possível, e aonde o "[...] peso do corpo imperceptivelmente e suavemente passava de uma perna para a

9 Working contractions (Stanislavski; Rumyantsev, 1998).

10 is performing in accordance with his inner feelings he must not be impeded in his movements by muscular contractions. The singer's whole attention must be centered in his action".

11 "[...] they must have some creative relationship to what you are doing".

12 "The singer-actor needs them fully as much as he does his daily vocalization exercises, Stanislavski would say".

13 "graceful fluidity"(Stanislavski, Rumyantsev, 1998, p. 06). 
outra sem o menor solavanco" (STANISLAVSKI; RUMYANTSEV, 1998, p. 06)'14. Depois, ia-se até um andamento rápido, quase uma corrida. Era trabalhada, assim, a percepção musical do corpo, com diferentes tipos de "velocidades".

0 aprendizado de danças também foi utilizado por Stanislavski no Estúdio assim como a esgrima. Atividades para os braços e mãos foram usadas de maneira similar ao treinamento do balé, porém imbuídas de "propósito": cada gesto não deveria ser belo por si mesmo se não estivesse ligado a uma imaginação ou motivação interior de cada artista. Esse pensamento se seguiu para todas as práticas, tais como vocalização, discurso, exercícios físicos, como já foi possível constatar anteriormente.

Outro objetivo a ser atingido no trabalho de treinamento com os jovens cantores-atores era uma boa dicção. Segundo o diretor, através da dicção precisa e expressiva, as palavras cantadas soariam claras e "coloridas"; o que asseguraria metade do sucesso de uma montagem (STANISLAVSKI; RUMYANTSEV, 1998). Aparentemente, alguns cantores não prestavam tanta atenção ao que de fato cantavam e na pronúncia do idioma (estrangeiro ou não) em detrimento de uma boa impostação e projeção vocal. Esta questão é colocada por Stanislavski não apenas no canto, mas ele mesmo já nela prestava atenção quando realizava suas operetas e vaudevilles amadores.

Já sobre o canto, ele era desenvolvido com base no texto e na música de forma a se procurar uma interpretação também física de cada canção. Ou seja, quando ele ensaiava com os cantores as baladas, ele as trabalhava a partir de duas bases principais: o texto e a música. Dessa forma, o texto, o significado de cada palavra deveria ser entendido e seus ápices ou palavras-chave destacadas; já a música seria a exigência última do compositor em retratar tais palavras. Percebe-se aqui um dos métodos que Stanislavski utilizava para encontrar o sentido das canções ou árias das óperas que montou: segundo ele, o texto é o "quê" e a música o "como". Assim, cada palavra não possui um significado único por si só; a música é a forma ultimada de definição de como aquele sentimento ou intenção deve ser interpretado pelo cantor.

Todas estas informações apresentadas sobre o Estúdio de ópera estão aqui reunidas para melhor compreender o trabalho que Stanislavski desenvolveu neste campo. Pode-se notar que toda uma estrutura foi a ele fornecida para que aprofundasse suas ideias na arte dramático-musical. Ele desenvolveu um treinamento voltado especificamente para os cantores-atores, a partir de seu sistema, e para que eles pudessem perceber em si mesmos seus potenciais criadores e, assim, modificar a prática de ópera com atuações embasadas num método consistente de atuação. Suas propostas para a ópera partiam, dessa forma, do cantor, da mudança de sua postura e atuação. 0 trabalho de Stanislavski na ópera, além de reconhecido na Rússia do período, deixou um legado que, embora nem sempre bem assimilado, trouxe mudanças significativas para a prática de ópera do século XX.

14 "[...] weight of the body imperceptibly and smoothly passed from one leg to the other without the slightest hitch". 
Constantin Stanislavski e o Estúdio de ópera do Teatro

Bolshoi: percursos e pensamentos sobre ópera

\section{Referências Bibliográficas}

> BONFITTO, Matteo. 0 ator compositor. São Paulo: Perspectiva, 2002.

> FERNANDINO, Jussara Rodrigues. Música e Cena: uma proposta de delineamento da música no teatro. Dissertação (Mestrado). Escola de Belas Artes, UFMG, Belo Horizonte, 2008.

> GUINSBURG, J. Stanislavski e o teatro de arte de Moscou: do realismo externo ao tchekhovismo. São Paulo: Perspectiva, 1985.

> STANISLAVSKI, Constantin. Minha vida na arte. Tradução: Paulo Bezerra. Rio de Janeiro: Civilização Brasileira, 1989.

> STANISLAVSKI, Constantin; RUMYANTSEV, Pavel. Stanislavski on Opera. Translation: Elizabeth Reynolds Hapgood. New York: Routledge, 1998.

> TAKEDA, Cristiane Layher. Minha vida na arte de Constantin Stanislavski: os caminhos de uma poética. Tese (Doutorado em Artes) - Programa de Pós-Graduação em Artes, Universidade de São Paulo, São Paulo, 2008.

Rosane Faraco Santolin, Mestranda em Teatro pelo PPGT/CEART-UDESC. Licencianda em Música pelo CEART-UDESC.

rosanesantolin@gmail.com 